\title{
Spatial and Temporal Analysis of Squash vein yellowing virus Infections in Watermelon
}

William W. Turechek, United States Department of Agriculture-Agricultural Research Service (USDA-ARS), U.S. Horticultural Research Laboratory, Fort Pierce, FL 34945; Pamela D. Roberts and Philip A. Stansly, Southwest Florida Research and Education Center, University of Florida, Immokalee 34142; Craig G. Webster, USDA-ARS, U.S. Horticultural Research Laboratory; Chandrasekar S. Kousik, USDA-ARS, U.S. Vegetable Laboratory, Charleston, SC 29414; and Scott Adkins, USDA-ARS, U.S. Horticultural Research Laboratory

\begin{abstract}
Turechek, W. W., Roberts, P. D., Stansly, P. A., Webster, C. G., Kousik, C. S., and Adkins, S. 2014. Spatial and temporal analysis of Squash vein yellowing virus infections in watermelon. Plant Dis. 98:1671-1680.

Squash vein yellowing virus (SqVYV) is a whitefly-transmitted ipomovirus infecting watermelon and other cucurbits that was recently introduced to Florida. Effects on watermelon are devastating, with total vine collapse, often near harvest, and fruit rendered unmarketable by brown, discolored flesh. The epidemiology of SqVYV was studied in a 1-ha field of 'Fiesta' watermelon over six growing seasons (I to VI) to characterize the spatial patterning of disease and temporal rate of disease progress, as well as its association with Cucurbit leaf crumple virus (CuLCrV) and Cucurbit yellow stunting disorder virus (CYSDV), two additional whitefly-transmitted viruses that often occur with SqVYV. The field was scouted at regular intervals for the length of the season for incidence of virus and number of whiteflies. Incidence of SqVYV reached $100 \%$ during seasons I, II, and V and $20 \%$

SqVYV progressed in a characteristic logistic fashion in seasons I, II, and $\mathrm{V}$ but less so in season III. The rate of disease progress was similar for the three seasons with high disease incidence, with an average value of 0.18 . A positive correlation between the area under the disease progress curve and whitefly-days was found, where both progress curves were calculated as a function of thermal time (degree days, base $\left.0^{\circ} \mathrm{C}\right)$. SqVYV displayed significant but variable levels of aggregation, as indicated by its fit to the $\beta$-binomial distribution, the binary power law, and ordinary runs analysis. Association analysis indicated that the viruses were largely transmitted independently. Results of this study provide epidemiological information that will be useful in the development of management strategies for SqVYV-induced vine decline, and provide new information for $\mathrm{CuLCrV}$ and CYSDV.
\end{abstract} during season III. SqVYV did not occur during seasons IV and VI.
Florida is one of the leading producers of watermelon (Citrullus lanatus Thunb.) in the United States and the primary supplier of fruit in the winter season. During the past decade, watermelon and some other cucurbit crops in the state have been affected by Squash vein yellowing virus (SqVYV), an ipomovirus first identified in 2005 as the cause of watermelon vine decline (3). The virus is transmitted by the whitefly Bemisia tabaci, biotype B (31). In addition to watermelon, the virus can infect numerous other cucurbit species, including several common cucurbit weeds, some of which serve as reservoirs for SqVYV (4,5,33). Symptoms vary depending on host but, in watermelon, infection by SqVYV results in a rapid collapse of the plant (hence the name watermelon vine decline) that typically occurs as the crop nears harvest (1).

In Florida, SqVYV has often been found to co-occur with two additional whitefly-transmitted viruses: Cucurbit leaf crumple virus $(\mathrm{CuLCrV})$ and Cucurbit yellow stunting disorder virus (CYSDV). CuLCrV is a begomovirus that was discovered in cucurbit crops in the southwestern United States in $1998(10,14)$. In October 2006, the virus was found in central Florida on yellow straightneck and zucchini squash (Cucurbita pepo L.) and then in watermelon in southwest and west-central Florida in 2007 (6), in green bean plants adjacent to infected watermelon plants (2), and in some common cucurbit weeds $(4,5)$. CYSDV is a crinivirus first

Corresponding author: W. W. Turechek,

E-mail: william.turechek@ars.usda.gov

Accepted for publication 13 May 2014.

http://dx.doi.org/10.1094/PDIS-10-13-1094-RE

This article is in the public domain and not copyrightable. It may be freely reprinted with customary crediting of the source. The American Phytopathological Society, 2014. found in melon (Cucumis melo) in southern Texas and northern Mexico in 1999 and in Florida in watermelon and squash in 2007 $(16,24)$. More recently, it was determined that cucurbit weeds and pigweed were also hosts for CYSDV $(5,32,35)$. Like SqVYV, these two viruses are transmitted by the whitefly $B$. tabaci, biotype B, and CYSDV is also transmitted by $B$. tabaci, biotype Q $(22,31)$. SqVYV has been the most economically important of these three viruses in Florida (3).

These whitefly-transmitted viruses have largely supplanted the aphid-transmitted potyviruses Papaya ringspot virus type W (PRSV-W), Watermelon mosaic virus, and Zucchini yellow mosaic virus as the most significant viral diseases in watermelon production in the state. In the 2003-04 season (the single season where losses were calculated), losses to SqVYV-induced watermelon vine decline were estimated at U.S.\$60 to 70 million, affecting over half of the Florida crop (15). Estimates of losses attributable to $\mathrm{CuLCrV}$ or CYSDV in Florida have not been calculated. Management of SqVYV has proven to be difficult for a number of reasons. First, the appearance or severity of disease in any given season has been unpredictable. When it occurs, the rate of disease progress is typically rapid. Complicating matters are the subsequent introductions of $\mathrm{CuLCrV}$ and CYSDV. Although these two viruses have not been as destructive as SqVYV, they have the potential to cause serious losses given their economic significance in the regions where they are established (e.g., southwestern United States and Mediterranean Basin; 7,9,17). A significant increase in the use of insecticides to manage the whitefly vector has followed the introduction of SqVYV, CuLCrV, and CYSDV to Florida.

The objectives of this study were to characterize the spatial pattern and temporal rate of progress of SqVYV and to characterize its association with CuLCrV and CYSDV to gain a better understanding of the epidemiology of SqVYV in Florida. A better understanding of the spatial patterning of disease, temporal rate of disease progress, and the association of SqVYV with CuLCrV and 
CYSDV will facilitate development of strategies for improved disease management, which may include the development of a decision aid or forecasting model to predict the presence of virus or the whitefly vector that could be used to more precisely time insecticide applications. Quantitative descriptions of the spatial pattern provide the necessary information for development of sampling protocols to estimate disease incidence and for use in decision making. A more detailed understanding of the association among viruses will provide insight into transmission mechanisms.

\section{Materials and Methods}

Field establishment. A 1-ha field of 'Fiesta' watermelon was established at the University of Florida's Southwest Florida Research and Education Center (SWFREC) in Immokalee in each of six growing seasons: fall 2007, spring and fall 2008, spring and fall 2009, and spring 2010, hereafter referred to as seasons I to VI, respectively. The field was established in the same location each year and consisted of 18 raised and methyl-bromide-fumigated beds covered with black plastic mulch, except for the fall season (III) planting which was covered with white plastic mulch (Table 1). Beds were spaced on 3.6-m centers with plants spaced $90 \mathrm{~cm}$ apart within beds. Each bed measured $130.5 \mathrm{~m}$ in length. As the crop progressed, beds were paired and vines were trained to the center in each set of paired beds. Ultimately, the vines in neighboring beds intermixed, making it difficult to identify the original bed for any given plant or vine, particularly on symptomatic vines lying between beds. Thus, it was decided to treat the field as a set of nine double rows by combining neighboring beds for all assessments to maintain consistency among ratings (i.e., beds 1 and 2 were combined to form row 1 ; beds 3 and 4 were combined to form row 2, and so on). The field was fertilized with a 5-17-8 (NP-K) bottom mix at a rate of $900 \mathrm{~kg} / \mathrm{ha}$ followed by a top mix of 19-0-19 at a rate of $1,120 \mathrm{~kg} / \mathrm{ha}$. Fungicides were applied regularly during each season to manage fungal diseases. Despite the disease management regime, some diseases proved too difficult to manage well over the course of the season, as was the case with gummy stem blight (Didymella bryoniae) in season III (Table 1). No insecticides were applied. Weather variables were measured and recorded by an automated weather station located approximately $50 \mathrm{~m}$ from the field at SWFREC and operated and maintained by the Florida Automated Weather Network.

Disease and whitefly assessment. Each $130.5-\mathrm{m}$ bed was marked with spray paint prior to transplanting at every $1.5 \mathrm{~m}$ along its entire length to demarcate sampling units for disease assessment, resulting in 85 to 87 sampling units per row depending on the condition at the ends of each bed. Fields were scouted every 7 to 14 days for the incidence (presence or absence) of SqVYV, $\mathrm{CuLCrV}$, and CYSDV in each of the $1.5-\mathrm{m}$ sampling units beginning 7 to 14 days after transplanting and continuing until harvest or until the plants fully collapsed from SqVYV-induced vine decline. A sampling unit was labeled diseased if symptoms of the virus were present anywhere within the unit. Because each row of watermelon consisted of two joined beds, the row was scouted on both sides due to its width. Initial symptoms of virus were confirmed by nucleic acid hybridization assay, as described by Turechek et al. (26); and, once confirmed, subsequent ratings were made based on symptoms or reverse-transcription polymerase chain reaction (4).

Whiteflies were monitored every 7 to 14 days by counting the number trapped on 7.5-by-12.5-cm yellow sticky cards, starting at transplanting and continuing until harvest or until all plants collapsed from SqVYV-induced vine decline (except for season I, where the first counts were initiated approximately 6 weeks after transplanting). Four yellow sticky cards were placed equidistant from each other down the center of each double-bed row for a total of 36 cards per planting. In addition, the population on plants was assessed by counting the number of whiteflies on three leaves on each of four plants located in the vicinity of the yellow sticky card for each card within the planting; these will subsequently be referred to as leaf-flip counts. In total, 432 leaves were assessed at each date.

Temporal progress. A linearized logistic model was fit to the disease progress data for SqVYV for each growing season to estimate the rate of disease progress, $r_{\mathrm{L}}(21)$ :

$$
\operatorname{logit}(p)=\operatorname{logit}\left(p_{0}\right)+r_{\mathrm{L}} t
$$

where $p$ is the incidence of SqVYV at time $t$ (days $^{-1}$; not degree days) and was estimated as the proportion of sampling units with symptoms, $p_{0}$ is initial disease incidence and was estimated as part of the intercept term-that is, $\operatorname{logit}\left(p_{0}\right)$-and the logit transformation is $\operatorname{logit}(z)=\ln [z /(1-z)]$. The intercept and slope parameters were estimated using linear regression (Minitab ver. 16). The logistic model was not fit to the CuLCrV or CYSDV data because the range of incidence was too small.

The area under the disease progress curve $\left(\mathrm{AUDPC}_{t}\right)$ was calculated for SqVYV as a function of thermal time (degree days, base $0^{\circ} \mathrm{C}$ ) for each growing season based on the proportion of infected sampling units (the $t$ subscript is to distinguish this measure from the standard AUDPC which is normally calculated as a function of time). In addition, whitefly-days $\left(\mathrm{WD}_{t}\right.$; base $\left.0^{\circ} \mathrm{C}\right)$ were calculated for whitefly counts on yellow sticky cards and for leaf-flip counts. $\mathrm{WD}_{t}$ is an analogous measure to AUDPC in that it summarizes the extent of whitefly dynamics over the course of the season (23). As above, the $t$ subscript is used to distinguish this measure from the standard whitefly-days. Because counting whiteflies ended at different times across the seasons (for various reasons), $\mathrm{WD}_{t}$ was measured up to the first count exceeding 1,500 degree days to standardize the measurement across seasons. A comparison of $\mathrm{AUDPC}_{t}$ to $\mathrm{WD}_{t}$ was made to determine the relationship between the two variables.

Spatial pattern analysis. Binomial and $\beta$-binomial distributions were fit to the data to characterize the spatial pattern of virus incidence at each assessment date where virus was observed. Separate analyses were conducted for SqVYV and CuLCrV; CYSDV was not analyzed because it occurred in only one season. The binomial distribution has parameters $\pi$ and $n$. The parameter $\pi$ is the probability that an individual (i.e., a $1.5-\mathrm{m}$ row segment) is diseased and is assumed to be constant over the area of study. The parameter $n$ is the number of sampling units in quadrat, which was defined to be $n$ $=4$ for this study (21). The $\beta$-binomial distribution has parameters $p, \theta$, and $n$. The parameter $p$ is the probability of disease but, unlike $\pi$ of the binomial distribution, $p$ is assumed to be a variable with a $\beta$ probability density given by $f(\pi)=\left(\pi^{\alpha-1}(1-\pi)^{\beta-1}\right) / \operatorname{Be}(\alpha, \beta)$, where $0<\pi<1$, the parameters $\alpha$ and $\beta$ are positive constants, and $\operatorname{Be}(\alpha, \beta)$ is the $\beta$ function. A common parameterization for the $\beta$ binomial distribution defines $p=\alpha /(\alpha+\beta)$ and $\theta=1 /(\alpha+\beta)$, where $\theta$ is a measure of overdispersion which is the variation in virus incidence $(p)$ among sampling units (21). When $\theta=0$, the $\beta$ binomial distribution reduces to the binomial distribution. A good

Table 1. Characteristics of an experimental field of 'Fiesta' watermelon located at the University of Florida Southwest Research and Education Center in Immokalee, Florida over six growing seasons from 2007 through 2010

\begin{tabular}{|c|c|c|c|c|c|}
\hline Season & Mulch & Planting date & First scouting date & Last scouting date & Problems observed \\
\hline I & Black & $10 / 18 / 2007$ & $11 / 27 / 2007$ & $1 / 2 / 2008$ & $\ldots$ \\
\hline II & Black & $3 / 4 / 2008$ & $3 / 18 / 2008$ & $6 / 5 / 2008$ & Herbicide damage \\
\hline III & White & $9 / 15 / 2008$ & $9 / 22 / 2008$ & $12 / 16 / 2008$ & Gummy stem blight (GSB) \\
\hline IV & Black & $3 / 9 / 2009$ & $3 / 26 / 2009$ & $6 / 3 / 2009$ & Hard freeze, Fusarium wilt \\
\hline V & Black & $9 / 14 / 2009$ & $9 / 22 / 2009$ & $11 / 30 / 2009$ & Downy mildew, GSB \\
\hline VI & Black & $3 / 17 / 2010$ & $4 / 8 / 2010$ & $6 / 3 / 2010$ & Hard freeze, poor weed control \\
\hline
\end{tabular}


fit to the binomial distribution is indicative of a random spatial pattern of virus incidence, whereas a good fit to the $\beta$-binomial distribution is suggestive of an aggregated or clustered pattern of virus incidence.

To fit the distributions to the data, the sampling units were combined into 1-by-4 non-overlapping quadrats. In total, each row yielded $N=21$ or 22 quadrats of $n=4$ sampling units at each observation date. If there was an extra sampling unit within each row (such that the total number of sampling units within a row was not divisible by four), the sampling unit was dropped. If there were two extra sampling units within each row, the last two sampling units were duplicated to produce another 1-by-4 quadrat (incidence
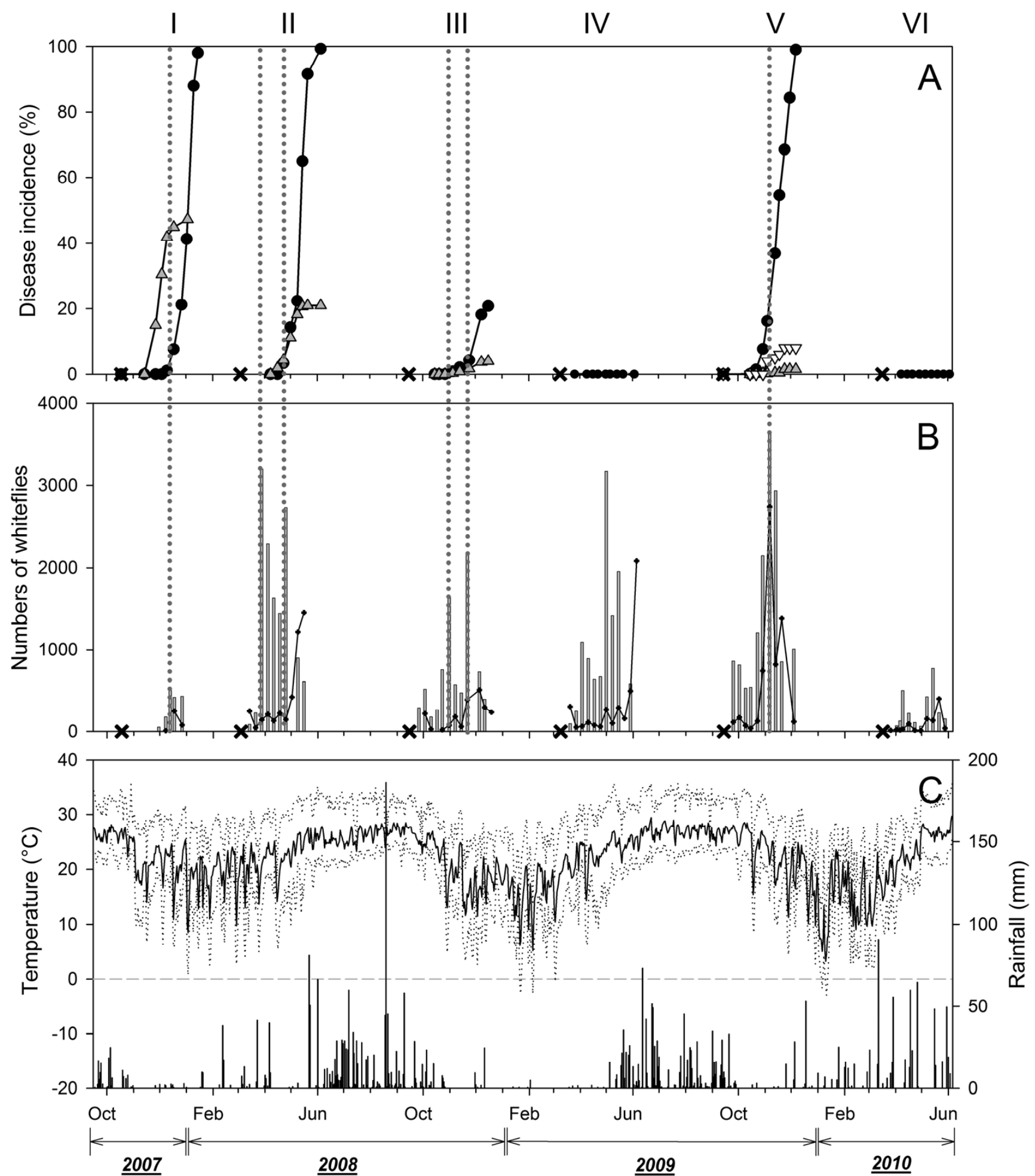

Fig. 1. A, Disease progress curves for Squash vein yellowing virus (-), Cucurbit leaf crumple virus $(\mathbf{\Delta})$, and Cucurbit yellow stunting disorder virus $(\nabla)$; $\mathbf{B}$, number of whiteflies trapped on 7.5-by-12.5-cm yellow sticky cards (line-and-scatter) and on the undersides of three leaves on each of four plants (bars) located in the vicinity around the yellow sticky cards within the planting; and $\mathbf{C}$, minimum (lower dotted line), mean (solid middle line), and maximum (upper dotted line) temperature $\left({ }^{\circ} \mathrm{C}\right.$ ) and daily rainfall totals (mm; solid bars) observed in an experimental field of watermelon located at the University of Florida Southwest Research and Education Center in Immokalee over six growing seasons from 2007 through 2010 (labeled I to $\mathrm{VI}$ at the top of the figure). A reference line of $0^{\circ} \mathrm{C}$ was added to $\mathrm{C}$ to allow easy identification of freeze events that occurred during two of the winter seasons. Gray dotted lines spanning the graphs are reference lines and correspond to disease incidence at the time of the highest numbers of whiteflies. The $\mathrm{x}$-markings on the $\mathrm{x}$-axis of $\mathbf{A}$ and $\mathbf{B}$ indicate the date of planting. 
does not change upon doubling). The quadrat data were fit to the binomial and $\beta$-binomial distribution using the program BBD (19). A log-likelihood ratio test statistic was calculated for each data set to test the hypotheses that the $\beta$-binomial fitted the data better than the binomial (20). Additionally, the index of dispersion, $D$, was calculated for each sampling date from the observed proportion of infected sampling units within quadrats. $D$ is a measure of aggregation similar to $\theta$ and is defined as the ratio of the observed variance $\left(v_{o b s}\right)$ to the variance expected if the data have a binomial distribution $\left(v_{\text {bin }}\right)\left(D=v_{\text {obs }} / v_{\text {bin }}\right)$. If data have binomial distribution, $D=1$.

Binary power law. The binary power law was used to characterize the relationship between $v_{o b s}$ and $v_{b i n}$ within each field. The binary power law was written as:

$$
\ln \left(v_{\text {obs }}\right)=\ln \left(A_{x}\right)+b \ln \left(v_{\text {bin }}\right)
$$

with $v_{\text {bin }}=n p(1-p)$ being the binomial variance where $n$ and $p$ are defined above, and the parameters $\ln \left(A_{x}\right)$ and $b$ are the intercept and slope of a straight line and were estimated by simple linear regression $(27,29)$. The parameters are interpreted such that if $A_{x}$ and $b$ equal 1 , the incidence of virus among sampling units is randomly distributed. If $b=1$ and $A_{x}>1$, virus incidence is aggregated and the degree of aggregation is independent of $p$. If $b$ and $A_{x}$ are greater than 1 , virus incidence is aggregated and the degree of aggregation changes with $p$. The power law was fit to the full set of data separately for SqVYV and CuLCrV, and then a covariance analysis was used to determine the effect of the factor season (i.e., any of the six individual growing seasons) on the power law parameters as described in Turechek and Madden (27). The power law was not fit to the CYSDV data because of too few observations.

Runs analysis. Ordinary runs analysis was used to analyze the pattern of virus-infected sampling units within rows. Separate analyses were conducted for SqVYV, CuLCrV, and CYSDV at each observation date. To perform the analysis, the rows for the entire field were first combined in a serpentine pattern such that total number of sampling units for the analysis was 775 . Virus-infected

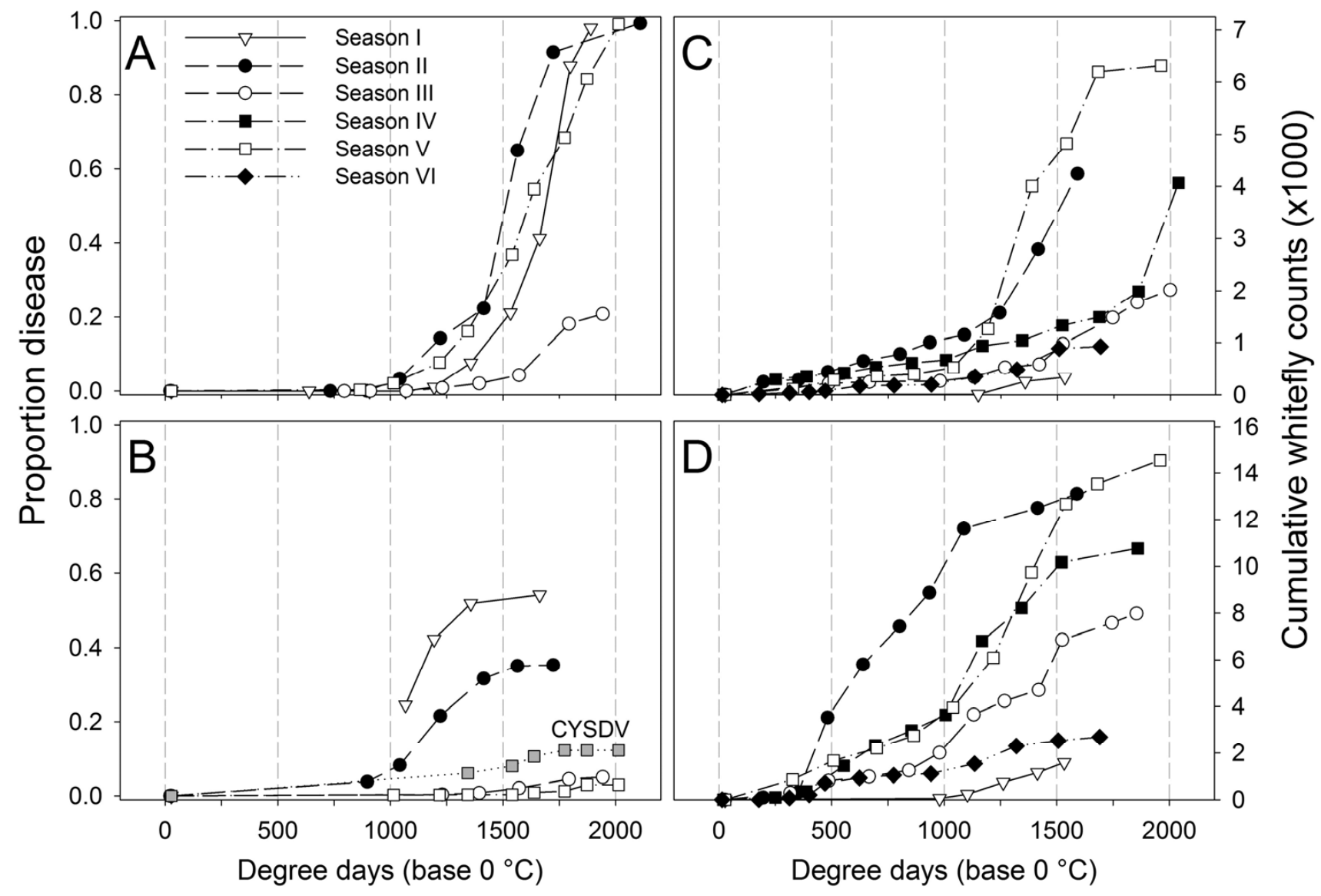

Fig. 2. Disease progress curves for A, Squash vein yellowing virus and B, Cucurbit leaf crumple virus and Cucurbit yellow stunting disorder virus, and cumulative whitefly counts C, trapped on yellow sticky cards and D, observed on the underside of 12 leaves (3 each on four plants) in the vicinity of the sticky cards in an experimental field of watermelon located at the University of Florida Southwest Research and Education Center in Immokalee over six growing seasons from 2007 through 2010 . Temporal progress is measured in terms of cumulative degree days (base $0^{\circ} \mathrm{C}$ ).

Table 2. Area under the disease progress curve (AUDPC $)$, intercept and slope $\left(r_{\mathrm{L}}\right)$ parameter estimates, associated standard errors (s.e.), and the coefficient of determination $\left(R^{2}\right)$ for fit to the logistic model of disease progress for epidemics of Squash vein yellowing virus (SqVYV) in 'Fiesta' watermelon plantings located at the University of Florida Southwest Research and Education Center in Immokalee, Florida for the four growing seasons between 2007 and 2010 where SqVYV was observed ${ }^{\mathrm{a}}$

\begin{tabular}{lllcccccc}
\hline ID & Year & Season & AUDPC $_{\boldsymbol{t}}$ & Intercept & s.e. & $\boldsymbol{r}_{\mathbf{L}}$ & s.e. & $\boldsymbol{R}^{\mathbf{2}}(\boldsymbol{\%})$ \\
\hline I & 2007 & Fall & 553.4 & -13.6 & 1.6 & 0.187 & 0.021 & 95.0 \\
II & 2008 & Spring & 702.3 & -11.4 & 1.4 & 0.176 & 0.019 & 95.6 \\
III & 2008 & Fall & 116.6 & -9.1 & 0.7 & 0.087 & 0.009 & 96.9 \\
V & 2009 & Fall & 599.2 & -11.5 & 0.8 & 0.182 & 0.013 & 96.4 \\
\hline
\end{tabular}

${ }^{a}$ AUDPC $_{t}$ was calculated for the progress curves based on degree-day accumulations shown in Figure 3C. Curves were standardized by adding the value 0.9999 at 2200 for seasons I, II, and V and the value 0.2100 (an increase of 0.019) for season III. Estimates for $r_{\mathrm{L}}$ were obtained using points within logarithmic portion of the curve and were estimated using actual time as the independent variable, not degree days. 
sampling units were assigned a ' 1 ' and virus-free sampling units were assigned a ' 0 ', and then the number of runs was calculated. A run is a sequence of sampling units with the same infection status $(13,27)$. For example, the sequence 1-0-1-1-0-0-0-1-1 contains five runs (i.e., 1, 0, 1-1, 0-0-0, and 1-1). The total number of runs was compared with the expected number of runs to calculate a standard normal $Z$ statistic and test the null hypothesis of a random distribution of infected sampling units. Runs analyses are not a particularly powerful test but they are one of the few, simple-to-run tests for randomness based on the order of the sequence (13).

Association analysis. Pairwise associations among SqVYV, $\mathrm{CuLCrV}$, and CYSDV were quantified using the Jaccard index of similarity $(J)(18,28)$. For each virus pair, the Jaccard index was calculated using $J=a /(a+b+c)$, where $a$ represents the number of sampling units (i.e., each of the 1.5-m sections, not the 1-by-4 quadrats) where both viruses occurred, $b$ represents the number of sampling units where only the first virus occurred, and $c$ represents the number of sampling units where only the second virus occurred. Because the number of sampling units where neither virus occurred is not used in calculating the index, the index represents the probability of both viruses being present in the same sampling unit within the set of sampling units where either virus was present. The values of the index range from 0 to 1 , where values close to 1 are indicative of a high degree of association and values close to 0 represent dissociation. Values indicative of independence lie between the two extremes, with the specific values being depend-

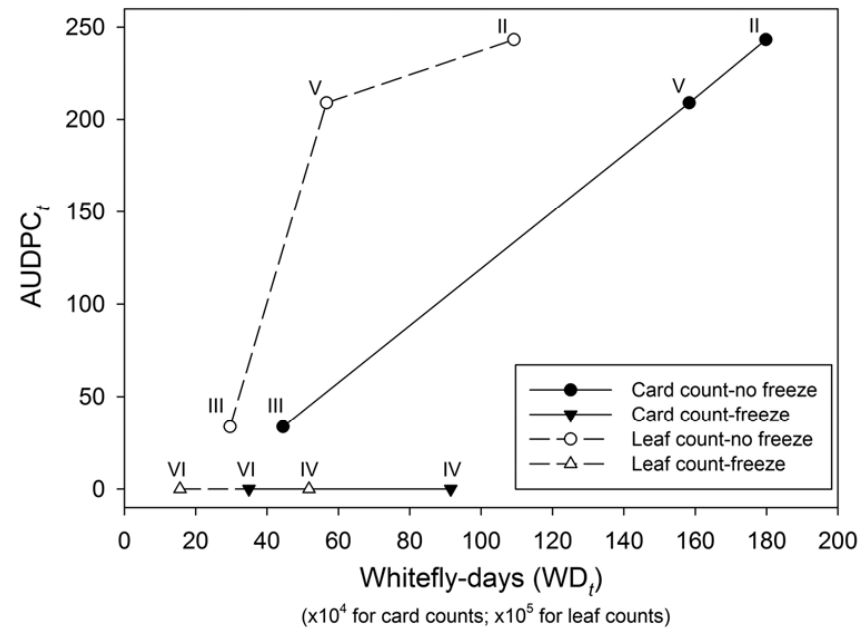

Fig. 3. Relationship between the area under the disease progress curve $\left(\mathrm{AUDPC}_{t}\right)$ and whitefly-days $\left(\mathrm{WD}_{i}\right.$; base $\left.0^{\circ} \mathrm{C}\right)$ based on the number of whiteflies trapped on sticky cards (solid symbols) or observed on leaf flips (open symbols) in an experimental field of watermelon located at the University of Florida Southwest Research and Education Center in Immokalee over six growing seasons from 2007 through 2010. Seasons were divided into two groups based on the occurrence of subfreezing temperatures prior to the start of the season. Whitefly days were standardized by summing the number of whitefly days accumulated at the first reading above approximately 1,500 degree days. Roman numeral above each data point indicates the field season the data was collected. ent on the incidences of the component viruses and the number of observations. The statistical significance of the index was tested by calculating a standard normal $Z$ statistic based on a nonparametric procedure fully described by Turecheck and Madden (28) and applying a two-sided $Z$ test.

\section{Results}

Disease and whitefly assessment. The incidence of SqVYV reached 100\% during seasons I (fall 2007), II (spring 2008), and V (fall 2009). SqVYV was not observed during seasons IV and VI (spring 2009 and 2010, respectively) and reached only 20\% incidence during season III (fall 2008) (Fig. 1A). The incidence of $\mathrm{CuLCrV}$ was highest during season I and was progressively lower in all following seasons (Fig. 1A). CYSDV was detected only in season $\mathrm{V}$ (Fig. 1A). Heavy rainfall prior to planting and an outbreak of gummy stem blight may have affected epidemic development in season III. The number of whiteflies on plants was generally high in all seasons (B. tabaci was the only whitefly species observed), with the sum across all 36 quarter sampling units exceeding 2,000 whiteflies at least once per season, except in season I, where counts did not begin until approximately 6 weeks after the planting was established (Fig. 1B), and season VI. Temperatures below freezing prior to seasons IV and VI were the likely factor affecting SqVYV and CuLCrV development in these growing seasons (Fig. 1C).

Temporal progress. SqVYV progressed in a characteristic logistic fashion beginning at approximately 1,000 degree days from planting in seasons I, II, and V and reaching nearly $100 \%$ incidence by the end of the season (Fig. 2A). In season III, virus incidence reached a maximum of $21 \%$, and no SqVYV was observed in seasons IV and VI. For the four seasons where SqVYV was observed, the logistic model fit the data well, with $R^{2}>95 \%$ (Table 2 ). In the three seasons with high virus incidence, the rate of disease progress $\left(r_{\mathrm{L}}\right)$ was similar, with an average value of 0.182 . The intercepts were also similar, with an average value of -12.2 . Disease progress curves for $\mathrm{CuLCrV}$ and for the single instance of CYSDV are shown for comparative purposes (Fig. 2B); no models were fit to these data. Cumulative whitefly counts observed on yellow sticky card traps and on the underside of leaves were somewhat variable across seasons (Fig. 2C and D). The highest counts observed on sticky cards occurred during seasons II and V, with a sharp increase in trap numbers being detected at approximately 1,200 degree days post planting (Fig. 2C). Season IV, a season where SqVYV did not occur, also had a high number of trapped whiteflies, but the greatest increase in trap numbers was observed at approximately 1,700 degree days post planting (Fig. 2C). Whitefly counts on the undersides of leaves were more variable than counts observed on sticky cards (Fig. 2D) but the highest leaf counts were observed during seasons where SqVYV occurred, with the exception of season I, where whitefly counts did not begin until 6 weeks post planting.

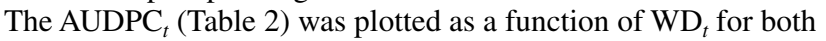
sticky card and leaf-flip counts, and was plotted separately for seasons experiencing preseason freeze events (Fig. 3). Season I was not included in this analysis because whitefly counts were not

Table 3. Mean values of virus incidence $(p)$, $\beta$-binomial aggregation parameter $(\theta)$, the index of dispersion $(D)$, and associated standard errors (s.e.) for epidemics of Squash vein yellowing virus (SqVYV) and Cucurbit leaf crumple virus (CuLCrV) in 'Fiesta' watermelon plantings located at the University of Florida Southwest Research and Education Center in Immokalee, Florida for the four growing seasons between 2007 and 2010 where viruses were observed

\begin{tabular}{|c|c|c|c|c|c|c|c|c|c|c|}
\hline Virus & ID & Year & Season & $n_{S}{ }^{\mathrm{a}}$ & $p$ & s.e. & $\theta$ & s.e. & $D$ & s.e. \\
\hline SqVYV & I & 2007 & Fall & 5 & 0.38 & 0.15 & 0.78 & 0.25 & 2.15 & 0.28 \\
\hline SqVYV & II & 2008 & Spring & 6 & 0.56 & 0.16 & 0.98 & 0.21 & 2.38 & 0.20 \\
\hline SqVYV & III & 2008 & Fall & 5 & 0.09 & 0.04 & 2.32 & 0.75 & 2.91 & 0.23 \\
\hline SqVYV & V & 2009 & Fall & 8 & 0.37 & 0.12 & 2.01 & 0.36 & 2.80 & 0.26 \\
\hline CuLCrV & I & 2007 & Fall & 5 & 0.45 & 0.06 & 0.95 & 0.18 & 2.39 & 0.18 \\
\hline CuLCrV & II & 2008 & Spring & 6 & 0.23 & 0.06 & 0.78 & 0.13 & 2.23 & 0.17 \\
\hline CuLCrV & III & 2008 & Fall & 5 & 0.03 & 0.01 & 2.68 & 0.76 & 2.95 & 0.33 \\
\hline CuLCrV & V & 2009 & Fall & 7 & 0.01 & 0.004 & 0.69 & 0.31 & 2.01 & 0.21 \\
\hline
\end{tabular}

${ }^{a}$ Number of scouting events used in calculating the average values. 
initiated until 6 weeks after planting. During seasons experiencing preseason freeze events, disease did not develop and $\mathrm{WD}_{t}$ was less than 100 for the first approximately 1,500 degree days since planting (the point at which these calculations were made to standardize comparison across seasons). If a freeze event did not occur, there was positive correlation between $\mathrm{AUDPC}_{t}$ and $\mathrm{WD}_{t}$ for both sticky card and leaf-flip counts.

Spatial pattern analysis. The $\beta$-binomial distribution described the distribution of SqVYV and CuLCrV better than the binomial distribution in $95.8 \%$ (23 of 24) and $100 \%$ (23 of 23) of the data sets (i.e., season by sampling date), respectively, according to the $\log$ likelihood ratio statistic. In seasons where SqVYV and CuLCrV developed, mean $p$ was 0.09 to 0.56 for SqVYV and 0.01 to 0.45 for CuLCrV (Table 3). For SqVYV, the relationship between $\theta$ and $p$ as well as between $D$ and $p$ followed the expected concave relationship (20), with higher values of $\theta$ being associated with virus incidences between 0.2 and 0.8 and lower values found at very low or very high incidences (Fig. 4A and C). That characteristic relationship was not evident with CuLCrV (Fig. 4B and D). This was partly due to $\mathrm{CuLCrV}$ incidence never exceeding 0.6 in any season, such that the functions for estimating $\theta$ and $D$ were not realized over the full range of $p$, and also due to the markedly different distribution of $\mathrm{CuLCrV}$ in season III, albeit still describable by a $\beta$-binomial distribution. This can also be seen among the seasonal averages for $\theta$ and, to a lesser extent, $D$ (Table 3 ).

Binary power law. The binary power law provided a good fit to the data for both SqVYV and CuLCrV, yielding parameter estimates consistent with an aggregated arrangement of virus inci- dence (Table 4). Estimated slope and intercept parameters were significantly greater than 0 and 1 , respectively, according to a $t$ test $(P<0.001)$, indicating that the degree of virus aggregation (i.e., $\theta)$ changed systematically with virus incidence. The covariance analysis indicated that the factor "season" had a significant effect on the intercept but not the slope parameters for both SqVYV and CuLCrV according to sequential $F$ tests (Table 5; Fig. 5A and B).

Table 4. Parameter estimates and their standard errors (s.e.) from the covariance models testing for the effect of the factor "season" on the intercept and slope parameters of the binary power law for epidemics of Squash vein yellowing virus (SqVYV) and Cucurbit leaf crumple virus (CuLCrV) in 'Fiesta' watermelon plantings located at the University of Florida Southwest Research and Education Center in Immokalee for the four growing seasons between 2007 and 2010 where viruses were observed

\begin{tabular}{lcccc}
\hline Virus, season & $\ln \left(\boldsymbol{A}_{\boldsymbol{x}}\right)$ & $\mathbf{s . e .} \ln \left(\boldsymbol{A}_{\boldsymbol{x}}\right)$ & $\boldsymbol{b}$ & s.e. $\boldsymbol{b}$ \\
\hline SqVYV & & & & \\
All & 1.104 & 0.068 & 1.156 & 0.038 \\
I (constant) & 0.873 & 0.082 & 1.187 & 0.029 \\
II & +0.194 & 0.108 & 1.187 & 0.029 \\
III & +0.501 & 0.115 & 1.187 & 0.029 \\
V & +0.349 & 0.102 & 1.187 & 0.029 \\
CuLCrV & & & & \\
All & 0.928 & 0.077 & 1.053 & 0.030 \\
I (constant) & 0.874 & 0.081 & 1.178 & 0.047 \\
II & +0.023 & 0.112 & 1.178 & 0.047 \\
III & +0.670 & 0.171 & 1.178 & 0.047 \\
V & +0.480 & 0.206 & 1.178 & 0.047 \\
\hline
\end{tabular}
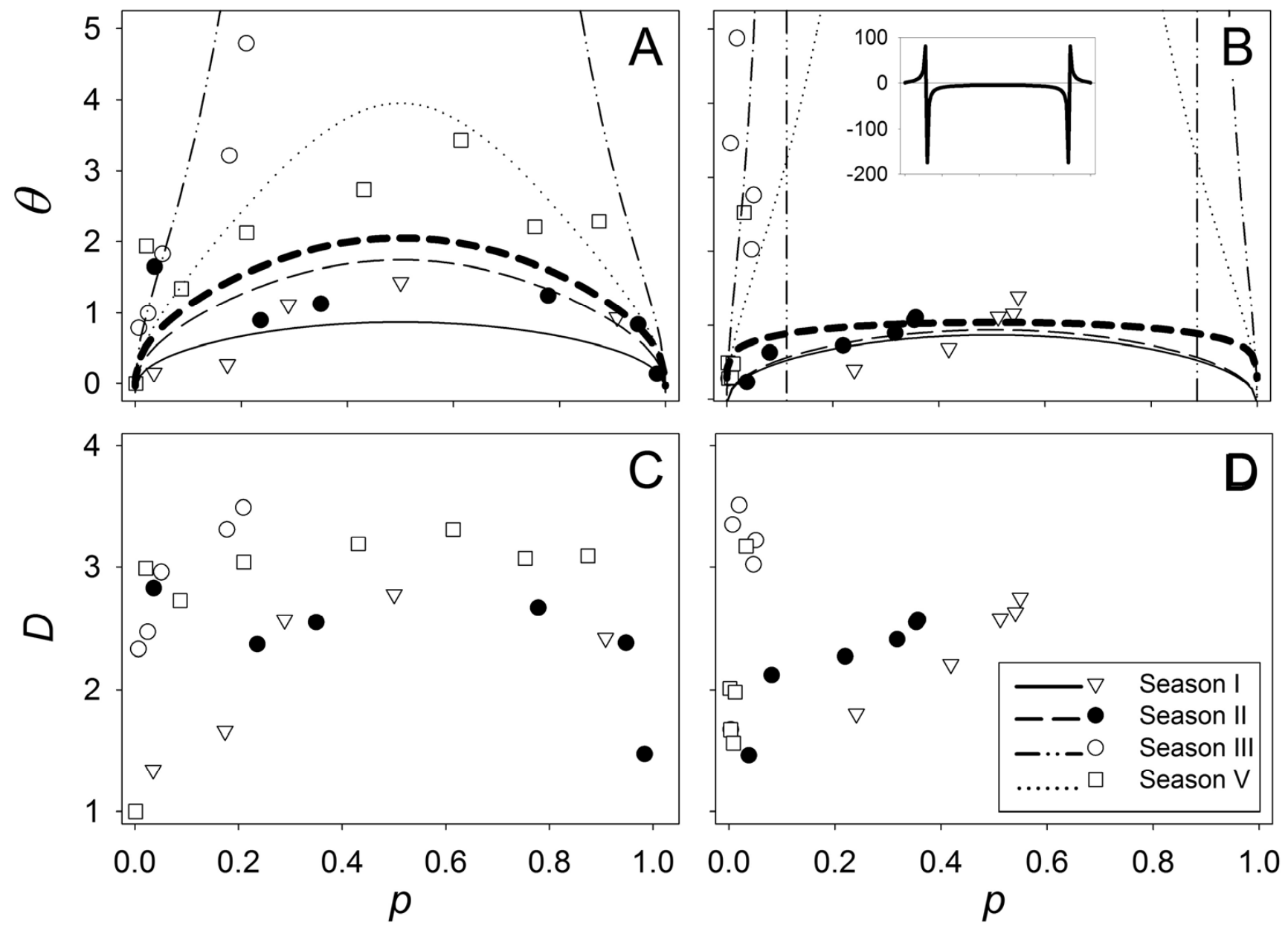

Fig. 4. Values of the $\beta$-binomial aggregation parameter $(\theta)$ and the index of dispersion $(D)$ for $\mathbf{A}$ and $\mathbf{B}$, Squash vein yellowing virus and $\mathbf{C}$ and $\mathbf{D}$, Cucurbit leaf crumple virus as a function of virus incidence in an experimental field of watermelon located at the University of Florida Southwest Research and Education Center in Immokalee for the four growing seasons between 2007 and 2010 where viruses were observed. Prediction curves for $\theta$ in $\mathbf{A}$ and $\mathbf{B}$ and were calculated using $\theta=[a-f(p) / n] /[f(p)-a]$, where a $\left(=A_{x} n^{b-2}\right)$ and $b$ are the power law parameters, adjusted specifically for each season, and $f(p)=[p(1-p)]^{1-b}$. Values of the power parameters are given in Table 4 . The inset in $\mathbf{B}$ is for the oddly shaped function in season III. Thickened dashed lines are estimates of $\theta$ independent of season (i.e., the average value). 
With the exception of a few observations from season III, the observed values of the dispersion parameter $\theta$ were reasonably close to predicted $\theta$ for SqVYV and CuLCrV for seasons I, II, and V when using the season-specific estimates of the slope from Table 4 (Fig. 5C and D), where the prediction of $\theta$ was calculated using the formula based on the power law parameters $a\left(=A_{x} n^{b-2}\right)$ and $b: \theta=$ $[a-f(p) / n] /[f(p)-a]$, where $f(p)=[p(1-p)]^{1-b}(20)$. In season III, predicted values of $\theta$ for SqVYV were uncharacteristically high for estimates within the midrange of incidence values (Fig. 4A). For
$\mathrm{CuLCrV}$, estimates of $\theta$ were not at all close to the observed values for season III and for observation in season V. However, more surprising was the very uncharacteristic, saddle-like shape for estimates of $\theta$ during season III (Fig. 4B and inset).

Runs analysis. With the exception of one SqVYV observation (where $p=0.0013$ ), all epidemics of SqVYV, CuLCrV, and CYSDV exhibited significantly fewer runs than expected (Fig. 6A). Although there is an appearance that deviations between the observed and expected number of runs was larger with increasing

Table 5. Results of a covariance analysis investigating the effect of the factor "season" on the intercept and slope parameters of the binary power law for epidemics of Squash vein yellowing virus (SqVYV) and Cucurbit leaf crumple virus (CuLCrV) in 'Fiesta' watermelon plantings located at the University of Florida Southwest Research and Education Center in Immokalee for the four growing seasons between 2007 and 2010 where viruses were observed $^{\mathrm{a}}$

\begin{tabular}{|c|c|c|c|c|c|c|c|c|c|c|}
\hline \multirow[b]{2}{*}{ Virus } & \multicolumn{2}{|c|}{ Error } & \multicolumn{4}{|c|}{$\operatorname{Intercept}\left[\ln \left(A_{x}\right)\right]$} & \multicolumn{4}{|c|}{ Slope (b) } \\
\hline & df & Seq SS & df & Seq SS & $\boldsymbol{F}$ & $P$ & df & Seq SS & $F$ & $P$ \\
\hline \multicolumn{11}{|l|}{ SqVYV } \\
\hline Power law & 22 & 1.27 & 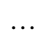 & & & & 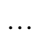 & & & \\
\hline +Season & 16 & 0.51 & 3 & 0.68 & 7.08 & 0.003 & 3 & 0.08 & 0.86 & 0.483 \\
\hline \multicolumn{11}{|l|}{ CuLCrV } \\
\hline Power law & 21 & 1.29 & $\ldots$ & $\ldots$ & $\cdots$ & & $\ldots$ & $\ldots$ & $\ldots$ & $\ldots$ \\
\hline +Season & 15 & 0.48 & 3 & 0.70 & 7.34 & 0.003 & 3 & 0.11 & 1.10 & 0.380 \\
\hline
\end{tabular}

${ }^{\mathrm{a}}$ Error $=$ mean squared error, $\mathrm{df}=$ degrees of freedom, Seq $\mathrm{SS}=$ sequential sums of squares, $F=F$ tests, and $P=P$ value.
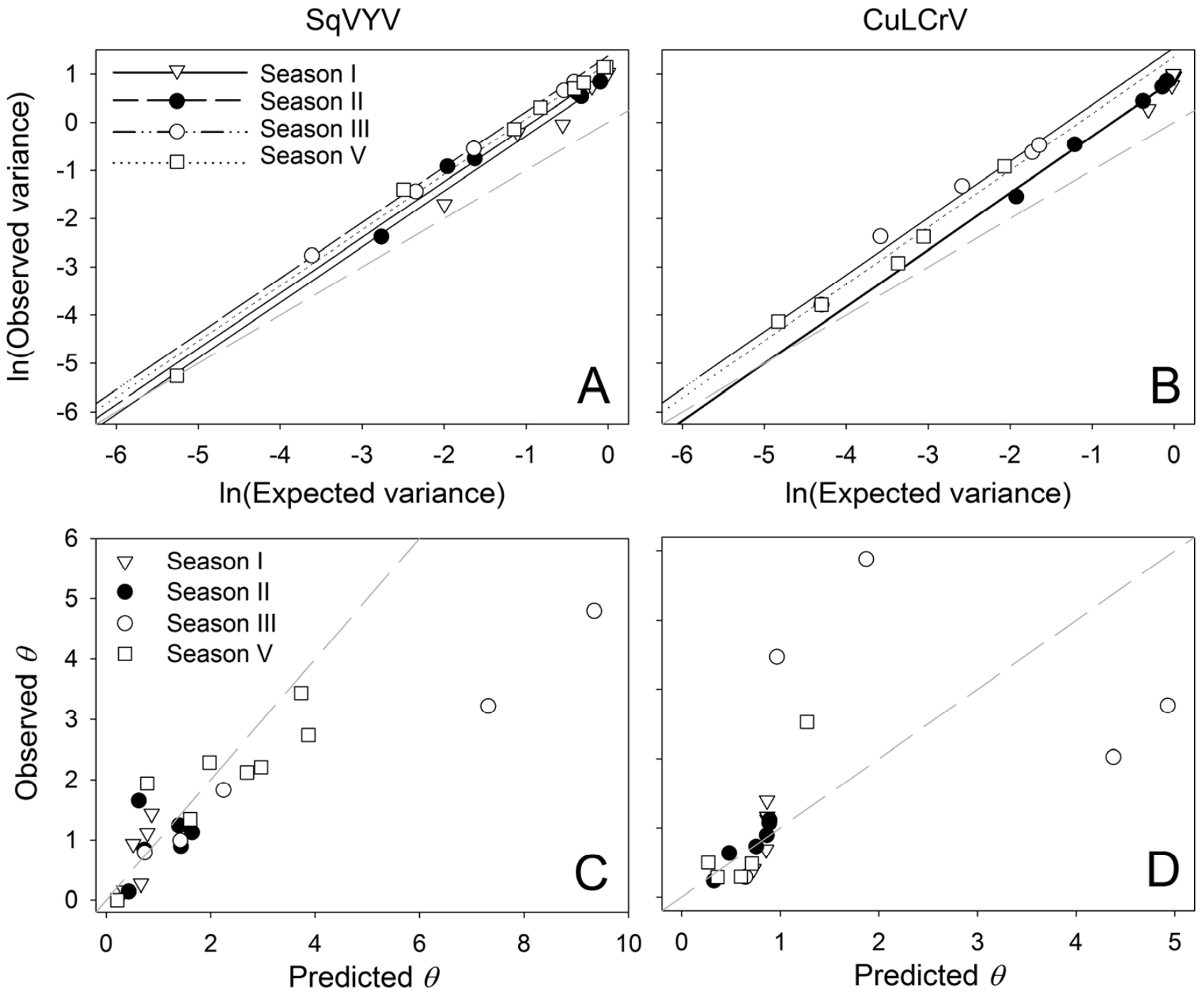

Fig. 5. A and B, Relationship between the logarithm of the observed variance and logarithm of the theoretical variance for a binomial distribution of the incidences of Squash vein yellowing virus (SqVYV) and Cucurbit leaf crumple virus (CuLCrV), respectively, observed in an experimental field of watermelon located at the University of Florida Southwest Research and Education Center in Immokalee for the four growing seasons between 2007 and 2010 where viruses were observed. Observed data are shown as open symbols and represent individual assessments of the disease at each rating date. The different lines represent the least-squares fit to the data with parameters given in Table 4. $\mathbf{C}$ and $\mathbf{D}$, Relationship between estimated $\theta$ of the $\beta$-binomial distribution and predicted $\theta$, where predicted $\theta=[a-f(p) / n] /[f(p)-a]$, where $a\left(=A_{x} n^{b-2}\right)$ and $b$ are the power law parameters, estimated specifically for each season, and $f(p)=[p(1-p)]^{1-b}$. The dashed gray line is the line $y=x$. 
virus incidence, the relative differences, calculated as (observed expected)/expected, were random across the range of incidence according to simple linear regression $(P=0.089$; Fig. 6B).

Association analysis. The magnitude of association between SqVYV and CuLCrV increased linearly with rating date for seasons I, II, and III and, with the exception of the first rating, did for season $\mathrm{V}$ as well (Fig. 7A). The anomalous value in season $\mathrm{V}$ was due to the low incidence of virus observed during the first rating and the fact that, in one of the six sampling units where virus was observed, the two viruses occurred together (giving a $J=1 / 6=$ 0.167). The magnitude of association between CYSDV and SqVYV or CuLCrV was fairly consistent over the observation dates in season $\mathrm{V}$, where the disease was observed, and was slightly higher for the SqVYV and CYSDV relationship than for CuLCrV (Fig. 7B). Significant associations according to the randomization test for the Jaccard index are indicated by asterisks. Significant associations, when they occurred, were always smaller than expected for the SqVYV-CuLCrV relationship and higher for the one occurrence for SqVYV-CYSDV. Observed values of $J$ were generally very close to the expected values of $J$, except in season $\mathrm{V}$, where they tended to be higher but not significantly, according to the randomization test (Fig. 7C).

\section{Discussion}

The spatial and temporal characteristics of SqVYV varied but were predictable over the course of the six growing seasons studied. Weather conditions and whitefly dynamics were identified as the primary causes of the variation in this study. It appears that the
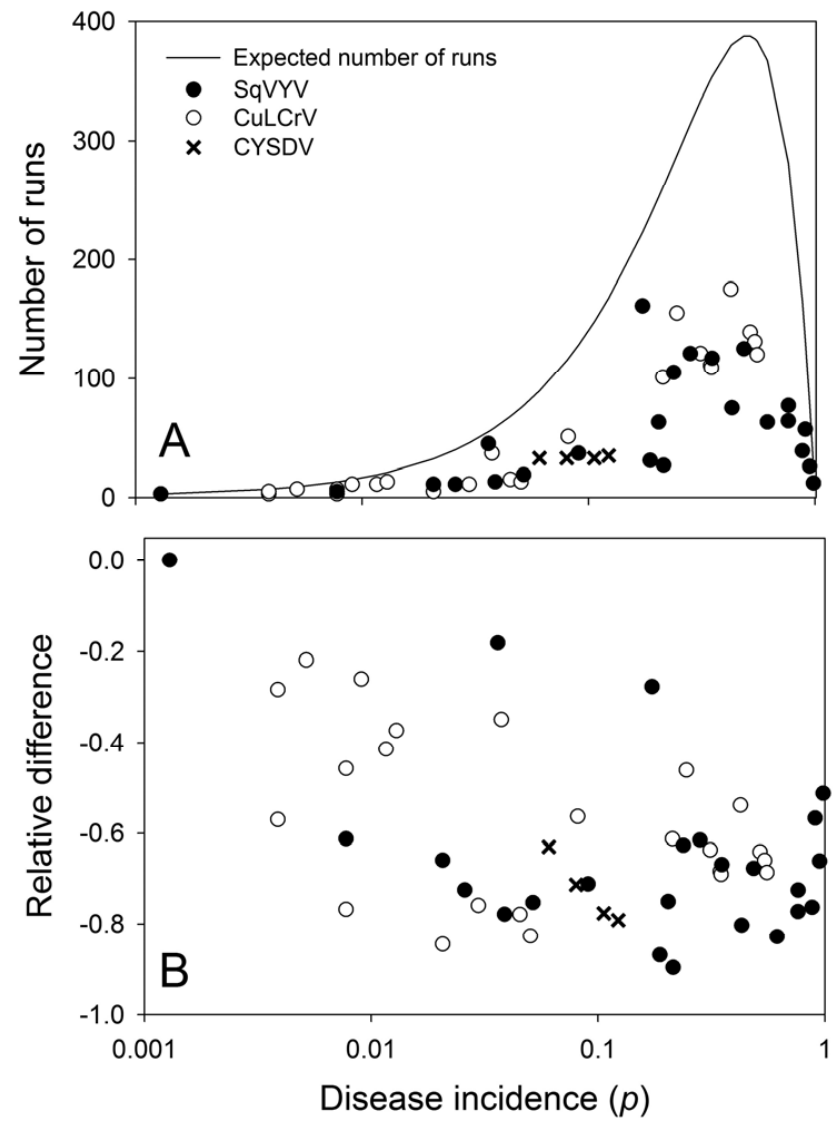

Fig. 6. Relationship between virus incidence and $\mathbf{A}$, the observed and expected number of runs and $\mathbf{B}$, the relative difference between the observed and expected number of runs for Squash vein yellowing virus (SqVYV), Cucurbit leaf crumple virus (CuLCrV), and Cucurbit yellow stunting disorder virus (CYSDV) in an experimental field of watermelon located at the University of Florida Southwest Research and Education Center in Immokalee for the four growing seasons between 2007 and 2010 where viruses were observed. The relative difference was calculated as [(observed number of runs - expected number of runs)/expected number of runs]. most influential weather variable affecting epidemic development was the occurrence of subfreezing temperatures in the winter months preceding planting. In seasons IV and VI, the subfreezing temperatures that occurred during those two winters hampered epidemic development the following spring in both our field planting and the vegetable industry in southwest Florida. Unfortunately, it was not clear from the data how severe the cold event must be to cause a significant reduction in disease or whiteflies, nor was it clear what was specifically affected by the cold weather. In season VI, the whitefly population was reduced and this quite logically could explain the absence of disease. However, this explanation did not apply to every season because the whitefly population in season IV was very similar to those in other seasons. Other explanations may be that the cold weather affected the virus population surviving in reservoir hosts or the reservoir hosts themselves. $\mathrm{Cu}-$ curbits, including cucurbit weeds, are particularly susceptible to cold temperature and many die back to the ground when subfreezing temperatures occur.

In considering epidemic development as a function of degree days, whiteflies were first observed on leaves shortly after planting, with noticeable accumulation around 400 degree days (except in season I, where counts did not begin until approximately 1,000 degree days had accumulated). In seasons with SqVYV, symptoms were consistently noticeable at approximately 1,000 degree days. At around 1,350 degree days in seasons II and V, whiteflies were being detected at higher densities on yellow sticky cards. This corresponded to the exponential increase in disease, where it was likely that whiteflies were in flight searching for new host tissue in response to collapsing plants and simultaneously moving the virus. It is possible that the same relationship existed in season I but whitefly counts started later and ended earlier than in other seasons due to lack of prior planning. However, independent assessment of whitefly populations on sticky cards from transplant houses in the area were obtained from a local scouting company, and the data indicated that whitefly population dynamics during season I were similar to those observed in season III, suggesting lower density and later flight times during season I. The later flight time would explain the slightly delayed onset of disease.

Heavy rains from tropical storm Faye preceded season III, during which SqVYV occurred at much lower incidence than the other three seasons where epidemics occurred. Tropical storm Faye produced nearly $25 \mathrm{~cm}$ of rain in southwest Florida. It is possible that the heavy rains and associated flooding impacted whitefly development or movement of whiteflies or SqVYV (and CuLCrV) into the experimental field. The whitefly density during season III was lower than seasons II and V, two seasons with near $100 \%$ disease and high counts of whiteflies, but it is not clear whether this reduction was due to Faye. The heavy rain favored development of a gummy stem blight epidemic in the field which was difficult to manage. Thus, it is possible that whiteflies were deterred from the diseased planting or that SqVYV or CuLCrV development was affected by co-infection with the fungal pathogen.

For the three seasons not affected by cold weather or heavy rain, the temporal progress of SqVYV was rapid (Fig. 2A), increasing from 5 to $90 \%$ in approximately 30 days. This is the expected rate of virus progression when a susceptible cultivar, which includes Fiesta and all other commercial watermelon cultivars tested (C. S. Kousik, P. D. Roberts, and S. Adkins, unpublished data), is grown in the absence of vector control (no insecticides were used in this study). The temporal progress of CuLCrV and CYSDV, the latter occurring in only one season, was different from SqVYV in both the rate of disease progress and maximum level of virus incidence (Fig. 2A and B). It is likely that the development of CuLCrV or CYSDV was impaired by the loss of plant tissue resulting from the rapid collapse of plants infected with SqVYV. At a minimum, the predominantly foliar symptoms of $\mathrm{CuLCrV}$ and CYSDV were obscured or lost during SqVYV-induced wilt and necrosis. Due to this bias in the $\mathrm{CuLCrV}$ and CYSDV data, we refrained from presenting extensive temporal analyses of $\mathrm{CuLCrV}$ and CYSDV in this article. 
Despite their ability to fly, whiteflies tend to move only short distances once they have found a suitable host and this was manifested in the distribution of virus $(8,11)$. SqVYV and CuLCrV displayed an aggregated spatial pattern but the degree of aggregation varied among seasons and was different between the two viruses according to models fit to the $\beta$-binomial distribution and estimates of power law parameters and associated covariance analysis. It is typical for the $\beta$-binomial parameter $\theta$ to be written as a function of the power law parameters (21). For SqVYV, it is recommended that the average value of the intercept be used (Table 4, listed under "All") because the covariance analysis indicated a significant seasonal effect on the intercept parameter, and the average captures a range of seasonal variability. Although power law parameters were estimated for $\mathrm{CuLCrV}$, their use in subsequent model development should be done with caution because of the atypical results that season III values contributed to the overall results, as shown by the saddle-shaped function that resulted for estimating $\theta$ for season III data (Fig. 4B, inset). From a mathematical perspective, this function shape arises when the function $f(p)$ approaches and crosses the binary power law parameter $a$.

In this study, the association between SqVYV and CuLCrV and between SqVYV and CYSDV was found to be significant in just 24 and $25 \%$ of the cases, respectively, suggesting that SqVYV,
$\mathrm{CuLCrV}$, and CYSDV were being acquired or transmitted mostly independently. This was a somewhat surprising result given that all three viruses are vectored by the same species of whitefly $(B$. tabaci) and that the viruses are known to infect many cucurbit crops and weeds (4,5). Moreover, Turechek et al. (26) found a high degree of association between SqVYV and CuLCrV in individual plants. There are several plausible explanations for these results. First, $\mathrm{CuLCrV}$ occurred at a higher incidence in Turechek et al. (26) than in the current study. For mixed infections, the efficiencies of transmission or the ability to multiply in the host can be quite variable and are functions of both virus titer and host characteristics, as has been shown to occur with Tomato infectious chlorosis virus and Tomato chlorosis virus in tomato $(12,34)$ and between Squash leaf curl virus and Watermelon chlorotic stunt virus on melon (25). The current and previous studies were also in different fields and in different locations. The study of Turechek et al. (26) was conducted in a small section of a much larger commercial planting of watermelon where whitefly management was practiced. Furthermore, the 2010 study occurred during a peak year of both SqVYV and CuLCrV infection. In the current study, a local source of SqVYV-infected watermelon was located approximately $1 \mathrm{~km}$ from the study (where other trials were being conducted). All of these factors, either individually or in some combination, could
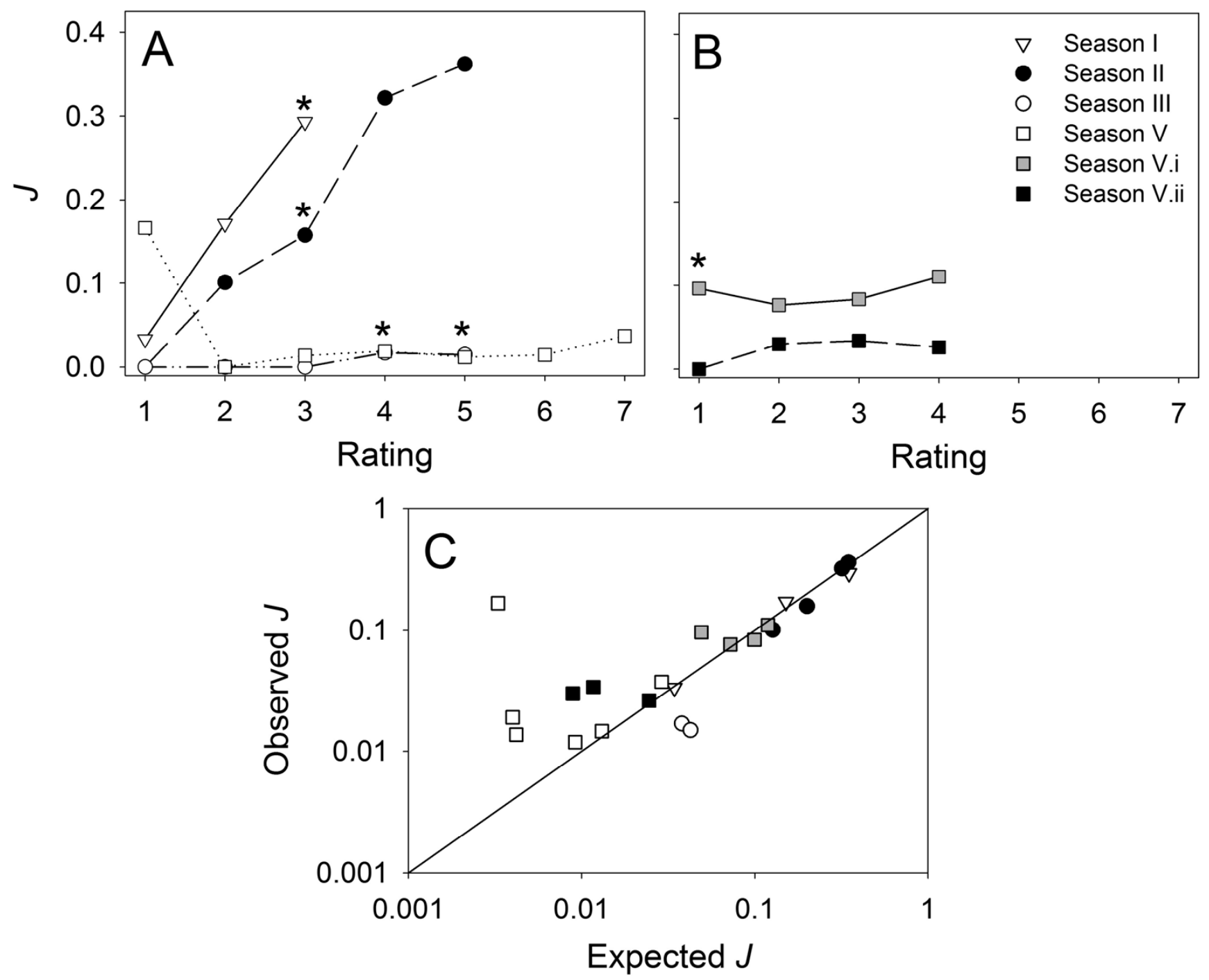

Fig. 7. Observed Jaccard similarity index for A, Squash vein yellowing virus and Cucurbit leaf crumple virus and B, Cucurbit yellow stunting disorder virus and Squash vein yellowing virus ( $\square$ ) or Cucurbit leaf crumple virus ( $\square$ ) in an experimental field of watermelon located at the University of Florida Southwest Research and Education Center in Immokalee for the four growing seasons between 2007 and 2010 where viruses were observed. Significant associations are indicated by asterisks. C, Relationship between the observed Jaccard similarity index, $\mathrm{J}$, and the expected value of the index under the assumption of independence for the combinations shown in A and B. The solid line in $C$ is the line $y=x$ and represents the value for independence. 
explain the differences in viral association. Finally, different diagnostic tests were employed in the two studies. In Turechek et al. (26), tissue blot nucleic acid hybridization assays (TB) were used for virus detection and identification in plant pieces, whereas visual symptoms were relied upon for the surveys in the current study. Turechek et al. (30) showed that TB had a higher sensitivity and lower specificity than the use of symptoms as a diagnostic test for SqVYV, meaning that a greater number of positive test results (both true and false) are likely with TB than with symptoms.

This study provided the necessary quantitative information on the temporal and spatial characteristics of SqVYV, and insight into climatic conditions that drive epidemic development to allow us to pursue the development of a sampling procedure and other predictive models for SqVYV-induced vine decline. SqVYV was clearly the dominant virus in this system and clearly affected both the temporal and spatial development of CuLCrV and CYSDV (for the single season in which it occurred). Thus, the epidemiological properties of $\mathrm{CuLCrV}$ described here are reflective of its development in the presence of SqVYV, and should not be interpreted to describe its development as if it were a single infection. For example, there is no reason to expect that the maximum level of disease incidence for $\mathrm{CuLCrV}$ will not exceed 0.45 , the highest value seen in this study. This also applies to CYSDV; however, only very limited spatial and no temporal analysis was done for this virus because it only appeared in one season. More detailed studies are needed to better elucidate the relationship between coinfection of SqVYV, CuLCrV, and CYSDV.

\section{Acknowledgments}

We thank B. Kostyk for collecting whitefly counts, R. Sytsma for field maintenance, and C. Vanderspool for excellent technical assistance with virus diagnostic tests. Financial support was provided, in part, by the United States Department of Agriculture Cooperative State Research, Education, and Extension Service SCRI grant 2008-04890 and the National Watermelon Association.

\section{Literature Cited}

1. Adkins, S., McCollum, T. G., Albano, J. P., Kousik, C. S., Baker, C. A., Webster, C. G., Roberts, P. D., Webb, S. E., and Turechek, W. W. 2013. Physiological effects of Squash vein yellowing virus infection on watermelon. Plant Dis. 97:1137-1148.

2. Adkins, S., Polston, J. E., and Turechek, W. W. 2009. Cucurbit leaf crumple virus identified in common bean in Florida. Plant Dis. 93:320.

3. Adkins, S., Webb, S. E., Achor, D., Roberts, P. D., and Baker, C. A. 2007. Identification and characterization of a novel whitefly-transmitted member of the family Potyviridae isolated from cucurbits in Florida. Phytopathology 97:145-154.

4. Adkins, S., Webb, S. E., Baker, C. A., and Kousik, C. S. 2008. Squash vein yellowing virus detection using nested polymerase chain reaction demonstrates that the cucurbit weed Momordica charantia is a reservoir host. Plant Dis. 92:1119-1123.

5. Adkins, S., Webster, C. G., Baker, C. A., Weaver, R., Rosskopf, E. N., and Turechek, W. W. 2009. Detection of three whitefly-transmitted viruses infecting the cucurbit weed, Cucumis melo var. dudaim, in Florida. Plant Health Progress. Online publication. doi:10.1094/PHP-2009-1118-01-BR

6. Akad, F., Webb, S., Nyoike, W., Liburd, O. E., Turechek, W., Adkins, S., and Polston, J. E. 2008. Detection of Cucurbit leaf crumple virus in Florida cucurbits. Plant Dis. 92:68.

7. Berdiales, B., Bernal, J. J., Saez, E., Woudt, B., Beitia, F., and Rodriguez Cerezo, E. 1999. Occurrence of cucurbit yellow stunting disorder virus (CYSDV) and beet pseudo-yellows virus in cucurbit crops in Spain and transmission of CYSDV by two biotypes of Bemisia tabaci. Eur. J. Plant Pathol. 105:211-215.

8. Blackmer, L. L., and Byrne, D. N. 1993. Flight behaviour of Bemisia tabaci in a vertical flight chamber: Effect of time of day, sex, age and host quality. Physiol. Entomol. 18:223-232.

9. Brown, J. K., Guerrero, J. C., Matheron, M., Olsen, M., and Idris, A. M. 2007. Widespread outbreak of Cucurbit yellow stunting disorder virus in melon, squash, and watermelon crops in the Sonoran desert of Arizona and Sonora, Mexico. Plant Dis. 91:773.

10. Brown, J. K., Idris, A. M., Olsen, M. W., Miller, M. E., Isakeit, T., and Anciso, J. 2000. Cucurbit leaf curl virus, a new whitefly transmitted gem- inivirus in Arizona, Texas, and Mexico. Plant Dis. 84:809.

11. Byrne, D. N., and Blackmer J. L. 1996. Examination of short-range migration by Bemisia. Pages 17-28 in: Bemisia: 1995 Taxonomy, Biology, Damage, Control and Management. D. Gerling and R. T. Mayer, eds. Intercept, Andover.

12. Dalmon, A., Fabre, F., Guilbaud, L., Lecoq, H., and Jacquemond, M. 2009. Comparative whitefly transmission of Tomato chlorosis virus and Tomato infectious chlorosis virus from single or mixed infections. Plant Pathol. 58:221-227.

13. Gibbons, J. D. 1985. Nonparametric Methods for Quantitative Analysis, Second Edition. American Sciences Press, Inc., Columbus, OH.

14. Guzman, P., Sudarshana, M. R., Seo, Y.-S., Rojas, M. R., Natwick, E., Turini, T., Mayberry, K., and Gilbertson, R. L. 2000. A new bipartite geminivirus (begomovirus) causing leaf curl and crumpling in cucurbits in the Imperial Valley of California. Plant Dis. 84:488.

15. Huber, M. 2006. Taking vital vines. Citrus Veg. Mag. 70:22-24.

16. Kao, J., Jia, L., Tian, T., Rubio, L., and Falk, B. W. 2000. First report of Cucurbit yellow stunting disorder virus (genus Crinivirus) in North America. Plant Dis. 84:101.

17. Kou, Y.-W., Rojas, M. R., Gilbertson, R. L., and Wintermantel, W. M. 2007. First report of Cucurbit yellow stunting disorder virus in California and Arizona, in association with Cucurbit leaf crumple virus and Squash leaf curl virus. Plant Dis. 91:330.

18. Ludwig, J. A., and Reynolds, J. F. 1988. Statistical Ecology. John Wiley \& Sons, New York.

19. Madden, L. V., and Hughes, G. 1994. BBD-computer software for fitting the beta-binomial distribution to disease incidence data. Plant Dis. 78:536540 .

20. Madden, L. V., and Hughes, G. 1995. Plant disease incidence: Distributions, heterogeneity, and temporal analysis. Annu. Rev. Phytopathol. 33:529-564.

21. Madden, L. V., Hughes, G., and van den Bosch, F. 2007. The Study of Plant Disease Epidemics. American Phytopathological Society, St. Paul, MN.

22. McGrath, M. T. 2004. Diseases of cucurbits and their management. Pages 455-510 in: Diseases of Fruits and Vegetables: Diagnosis and Management, Vol. 1. S. A. M. H Naqvi, ed. Kluwer Publishers, Dordrecht, The Netherlands.

23. McKee, G. J., Zalom, F. G., and Goodhue, R. E. 2007. Management and yield impact of the greenhouse whitefly (Trialeurodes vaporariorum) on California strawberries. HortScience 42:280-284.

24. Polston, J. E., Hladky, L. L., Akad, F., and Wintermantel, W. M. 2008. First report of Cucurbit yellow stunting disorder virus in cucurbits in Florida. Plant Dis. 92:1251.

25. Sufrin-Ringwald, T., and Lapidot, M. 2011. Characterization of a synergistic interaction between two cucurbit-infecting begomoviruses: Squash leaf curl virus and Watermelon chlorotic stunt virus. Phytopathology 101:281-289.

26. Turechek, W. W., Kousik, C. S., and Adkins, S. 2010. Distribution of four viruses in single and mixed infections within infected watermelon plants in Florida. Phytopathology 100:1194-1203.

27. Turechek, W. W., and Madden, L. V. 1999. Spatial pattern analysis of strawberry leaf blight in perennial production systems in Ohio. Phytopathology 89:421-433.

28. Turechek, W. W., and Madden, L. V. 2000. Analysis of the association between the incidence of two spatially aggregated foliar diseases of strawberry. Phytopathology 90:157-170.

29. Turechek, W. W., Madden L. V., Gent, D. H., and Xu, X.-M. 2011. Comments regarding the binary power law. Phytopathology 101:1396-1407.

30. Turechek, W. W, Webster, C. G., Duan, J., Roberts, P. D., Kousik, C. S., and Adkins, S. 2013. The use of latent class analysis to estimate the sensitivities and specificities of diagnostic tests for Squash vein yellowing virus in cucurbit species when there is no gold standard. Phytopathology 103:12431251.

31. Webb, S. E., Adkins, S., and Reitz, S. R. 2012. Semipersistent whitefly transmission of Squash vein yellowing virus, causal agent of viral watermelon vine decline. Plant Dis. 96:839-844.

32. Webster, C. G., Kousik, C. S., Roberts, P. D., Rosskopf, E. N., Turechek, W. W., and Adkins, S. 2011. Cucurbit yellow stunting disorder virus detected in pigweed in Florida. Plant Dis. 95:360.

33. Webster, C. G., Kousik, C. S., Turechek, W. W., Webb, S. E., Roberts, P. D., and Adkins, S. 2013. Squash vein yellowing virus infection of vining cucurbits and the vine decline response. Plant Dis. 97:1149-1157.

34. Wintermantel, W. M., Cortez, A. A., Anchieta, A. G., Gulati-Sakhuja, A., and Hladky, L. L. 2008. Co-infection by two criniviruses alters accumulation of each virus in a host-specific manner and influences efficiency of virus transmission. Phytopathology 98:1340-1345.

35. Wintermantel, W. M., Hladky, L. L., Cortez, A. A., and Natwick, E. T. 2009 A new expanded host range of Cucurbit yellow stunting disorder virus includes three agricultural crops. Plant Dis. 93:685-690. 